\title{
Sandra Contreras y José Goity (coords.), Las humanidades por venir. Políticas y debates en el siglo XXI. Rosario, Humanidades y Artes Ediciones, 2020
}

Iván Suasnábar

Cita sugerida: Suasnábar, I. (2021). [Revisión del libro Las humanidades por venir. Políticas y debates en el siglo XXI por S. Contreras y J. Goity (coords.)] . Orbis Tertius, 26(34), e223. https://doi.org/10.24215/18517811e223

Los trabajos que integran este volumen formaron parte del Congreso Internacional Las humanidades por venir. Politicas y debates en el siglo XXI, que tuvo lugar los días 15, 16 y 17 de abril de 2019 en la Facultad de Humanidades y Artes de la Universidad Nacional de Rosario. El evento contó la presencia de destacados investigadores argentinos y del extranjero y tuvo como propósito central la necesidad de pensar los desafíos teóricos y políticos del campo de las humanidades en el mundo contemporáneo. Una tarea particularmente desafiante dado que, tal como señala José Goity en las "Palabras de presentación” del libro, "el nuevo milenio se presenta a nuestra experiencia como un tiempo cargado de preguntas e incertidumbres" (p. 8) que requiere, más que nunca, del compromiso de las humanidades. Asimismo, en el marco de una fuerte descalificación de la investigación científica por parte de las salientes autoridades del Poder Ejecutivo Nacional, el Congreso supuso una apuesta por reflexionar sobre ciertas tendencias que inciden actualmente en la producción y circulación del conocimiento humanístico, pero también sobre el contexto mismo en que se dieron estos debates. Vale decir, un contexto en el cual las ciencias humanas fueron objeto de un intenso cuestionamiento, mas no desde el punto de vista de una interpelación reflexiva sobre sus saberes constituidos sino, como bien señala Sandra Contreras en la "Introducción", "en el sentido, más elemental, de una puesta en duda descalificadora dentro del sistema científico en el que se inscriben como campo de investigación” (p. 12). 
Lejos de cualquier definición negativa que busque deslegitimar al conocimiento humanístico respecto de su función social, cada una de las intervenciones que integran este volumen viene a ofrecer - desde distintas perspectivas disciplinares - una muestra cabal de la potencia de las humanidades a la hora de imaginar no solo futuros posibles, sino nuevas articulaciones teóricas, epistemológicas y políticas entre conocimiento social, práctica científica y esfera pública.

El primer apartado, "Las humanidades y la circulación del saber", agrupa una serie de contribuciones que tienen como eje el vínculo entre conocimiento y nuevas tecnologías. Este es el caso de la conferencia de apertura de Néstor García Canclini, "Humanidades 2020. Ser ciudadanos en la era digital", donde el autor articula una respuesta sobre el devenir de las humanidades teniendo en cuenta que la tecnologización de los saberes ha resituado por completo la relación entre sujetos y conocimiento científico. En este sentido, García Canclini recorta dos debates -el determinismo biotecnológico y las mutaciones del capitalismo electrónico - frente a los cuales el pensamiento humanístico debe posicionarse desde una perspectiva actualizada, transdisciplinaria y atenta a la restitución de la política como debate sobre el sentido. En "Restos actuales. Desafíos digitales para las humanidades”, Nicolás Quiroga se interroga por el devenir de los archivos futuros, deteniéndose en el estudio de los datos y algoritmos. Así, el autor analiza el caso del archivo del sitio Web GeoCities con el objetivo de comprender la significación y el funcionamiento de estos archivos nacidos digitales y cuáles son los problemas teóricos y metodológicos que le plantean al estudio de las humanidades. En "Archivos y gestión documental: un asunto pendiente en la agenda oficial”, Beatriz Bragoni reflexiona sobre la relación entre prácticas de archivo y resultados de investigación, considerando la alteración sustancial que, en las últimas décadas, ha sufrido la investigación historiográfica a manos de las nuevas tecnologías que, así como facilitaron el estudio de fuentes primarias, han puesto en cuestión las políticas de gestión documental en un desigual escenario institucional para América Latina. En este sentido, la autora señala la necesidad de motorizar un repertorio de acciones con el objetivo de optimizar las condiciones de consulta de diversos fondos documentales y archivísticos. Por su parte, en "La traducción de libros de ciencias sociales y humanas entre Francia y Argentina como intercambio desigual”, Gustavo Sorá aborda los intercambios simbólicos entre ambas naciones, haciendo foco en las prácticas de traducción y de gestión editorial. Para ello, el autor consigna una serie de gráficos que dan cuenta de un mapa de relaciones que ofrece un diagnóstico del intercambio franco-argentino en el presente con el objeto de promover relaciones culturales más equilibradas. Finalmente, en "Las humanidades por-venir: derivas de algunos datos estadísticos y de algunos 'cuentos' (Argentina, 1958-2015)”, Analía Gerbaudo señala algunas conclusiones que se desprenden de una investigación sobre las dinámicas de institucionalización de los estudios literarios en Argentina. Para tal fin, la autora recorta cuatro dimensiones de análisis (enseñanza, investigación, publicaciones, organización profesional) que, en la larga duración, describen un estado del campo de las ciencias sociales y humanas que funciona como un espacio privilegiado para el ejercicio de nano-intervenciones.

El segundo apartado, "Humanidades, Universidad, pensamiento crítico", reúne tres intervenciones que reflexionan sobre el porvenir de las humanidades en el contexto universitario. Este es el caso de "Las humanidades y la Universidad", en donde Eduardo Rinesi aborda las tensiones entre humanidades y ciencias sociales en Argentina dando cuenta de las distintas modulaciones que adquirió el debate entre tradiciones positivistas y hermenéuticas. Asimismo, el autor reivindica un cierto grado de gratuidad del saber propio de las humanidades, en tanto este supone siempre una defensa del bien público que atenta contra toda concepción utilitarista. Por su parte, en "Humanidades: la universidad y lo público, la creación y la crítica", Pablo Oyarzún Robles reflexiona sobre el carácter innegociable del conocimiento científico producido por las humanidades. Para el autor, sin embargo, no se trata de realizar una defensa cerrada de la radical inutilidad del saber humanístico sino de evidenciar la necesidad de un espacio de libertad irrestricto para su despliegue. Por último, en "Historia de la transmisión crítica: un testimonio", Nora Catelli realiza un recorrido autobiográfico para indagar sobre los vínculos entre saberes y memoria de lecturas. Marcel Proust, Arno Schmidt y Antonio Di Benedetto son algunos de los escritores convocados en este ensayo, donde la 
autora reivindica el ejercicio de una lectura detenida, atenta a la percepción histórica de las series textuales y entendida siempre como un acto de transmisión indisolublemente ligado al destino de las humanidades.

El tercer apartado, "Humanidades y profesionalización", reúne tres intervenciones que indagan en la relación entre trabajo y conocimiento científico desde la perspectiva de la formación profesional. En "Las fronteras de la universidad y la transmisión de las humanidades y las ciencias sociales. Una incursión en los debates recientes y en el devenir de la profesión académica", Sandra Carli ofrece un panorama de algunas tendencias actuales que afectan a la educación superior en lo que refiere a los modos de producción del conocimiento, la cultura estudiantil y la formación académico-profesional de los sujetos universitarios. Al respecto, la autora plantea la necesidad de que la universidad se piense a sí misma como un repertorio abierto de saberes, capaz de indagar en el campo de las humanidades desde una perspectiva colaborativa, interdisciplinaria y ligada a la acción social. En "Universidad, formación profesional y educación en las humanidades", Eduardo Zimmermann aborda la relación entre formación, orientación profesional y mercado laboral a partir de un diagnóstico que identifica ciertos problemas actuales de la universidad pública, tales como la estructura académica, la duración de las carreras, los índices de deserción o la rigidez de los planes de estudio. Ante este panorama, el autor aboga por la introducción de un modelo de formación básica generalista en el nivel del grado que sea menos extenso, más flexible en términos de salida laboral y, sobre todo, que no apunte a la acumulación de saberes fijos sino al desarrollo de ciertas capacidades. Por su parte, en "Ética profesional y enseñanza del derecho, en el marco de sociedades desiguales”, Roberto Gargarella plantea una serie de debates relativos al ejercicio del derecho en contextos de polaridad social, cuyo efecto más evidente es el acceso desigual a la justicia. Para el autor, se trata de un fenómeno que no solo recrudece en contextos de alta corrupción institucional, sino que se retroalimenta de una enseñanza del derecho orientada fundamentalmente a la práctica, desligada de los aportes de la teoría y que, de no modificarse, seguirá reproduciendo las injusticias del orden social existente.

Bajo el título "Política de/en las humanidades", el cuarto apartado del libro nuclea una serie de intervenciones que reflexionan sobre distintos clivajes de lo político desde una perspectiva a la vez histórica y situada. En "Historia de una relación conflictiva: las mujeres y las humanidades", Dora Barrancos se refiere al lugar de subalternidad al que han sido relegadas las mujeres en la historia del conocimiento en lo que respecta a tres campos específicos: literatura, filosofía e historia. Así, contrariamente al sentido común que detecta una mayor discriminación en el área de las ciencias exactas y naturales, Barrancos señala que también las humanidades han sido reacias al reconocimiento profesional de las mujeres que, de más está decir, no fueron pocas, sino históricamente soterradas. En "Humanidades, ciencias sociales y política científica", Mario Pecheny y Luca Zaidan reivindican la práctica científica frente a ciertos ataques que se realizan contra las humanidades y las ciencias sociales. Evocando a Hannah Arendt -y su descripción de los tiempos sombrios como aquellos en los cuales el ámbito público se oscurece-, los autores realizan un llamado a no dejarse vencer por los mandatos de productividad neoliberal y a estar atentos frente a cualquier intento de restitución conservadora y sexo-genérica que atente sobre los cuerpos y los sujetos. Por su parte, en "Número y representación. Un argumento sobre la analogía colonial y las ciencias humanas", Alejandro de Oto reflexiona sobre los modos de categorización y los presupuestos epistemológicos del pensamiento social contemporáneo a partir de observar cómo estos dispositivos funcionan como máquinas de producir alteridades. En este sentido, el autor señala la necesidad de volver inteligible el contexto en el cual se producen los conocimientos, a fin de evitar las consabidas prácticas de imposición, segregación y diferenciación operadas por los colonialismos históricos.

Finalmente, el quinto y último apartado del libro, titulado "(Pos)Humanismos, (Pos)Humanidades", reúne cuatro intervenciones que imaginan modos de vida posible, así como nuevas articulaciones entre miembros de la comunidad viviente. Este es el caso de "Animales y mujeres en el camino de la deconstrucción de las humanidades en el poshumanismo”, donde Mónica Cragnolini invita a la deconstrucción del humanismo metafísico fundado en una noción de sujeto viril y carnívoro; deconstrucción que, para la autora, 
debe plantearse desde la convergencia de la lucha feminista y el problema de la animalidad, en tanto ambos activismos cuestionan fuertemente el paradigma androcéntrico y patriarcal de las humanidades, al tiempo que permiten imaginar modos de vida diversos y hospitalarios. Por su parte, en “¿Qué es el pueblo? ¿Qué son las plantas? El 'plantón móvil' de Lucía Monge”, Víctor Vich refiere una experiencia de arte participativo que tuvo lugar en Lima y consistió en la ocupación del espacio público por parte de un conjunto de árboles que - con la ayuda de decenas de personas - , marcharon por las calles de la ciudad, reclamando la ampliación del espacio verde urbano. Para el autor, la intervención buscó generar nuevas articulaciones políticas entre ciudadanos y plantas, al poner en cuestionamiento las fronteras entre sujeto y naturaleza. Por su parte, en "Lo inhumano en lo humano", Juan B. Ritvo plantea una interrogación ética sobre los límites últimos de lo humano al reflexionar sobre la segregación que lleva al sometimiento del prójimo; una fuerza que, pese a su carácter destructivo, bien puede ser sublimada — dice el autor, siguiendo a Hegel — si logra transformarse en negatividad. Cierra este apartado la intervención de José Emilio Burucúa, "Vislumbres de un futuro útil y enaltecedor para las humanidades", donde el autor recurre a una serie de imágenes fechadas en distintos momentos históricos, con el objeto de definir un nuevo tipo de alianza entre artes y ciencias. Para Burucúa, se trata de realizar una apelación a romper el cerco de las humanidades para convertirlas en otra cosa; a saber, en una suerte teodicea secular sólida capaz de reconciliar las polaridades y de velar por el sufrimiento de los débiles e inocentes.

"En las Humanidades, se piensa la irreductibilidad de su afuera y de su porvenir", afirmó Jacques Derrida en "El porvenir de la profesión. La Universidad sin condición”, transcripción de una conferencia pronunciada en la Universidad de Stanford, en abril de 1998. En esta cita se condensa, podríamos decir, no solo el fundamento de la convocatoria del Congreso sino el espíritu mismo que anima cada una de las intervenciones que acaban de reseñarse; una profesión de fe en las humanidades que - como bien señala Contreras en su ya mencionada Introducción-, comienza por "volver a afirmar el principio de libertad incondicional del pensamiento que se produce y circula en la universidad” (p. 17). Una resistencia sin condiciones respecto de cualquier forma de imposición; un llamado a seguir pensando el porvenir — humanístico, institucional, afectivo- de nuestra vida en común. 